\title{
Unusual drainage pattern of a supracardiac total anomalous pulmonary venous connection
}

\author{
Naveen Chandra Ganiga Sanjeeva, ${ }^{1}$ Achyut Sarkar, ${ }^{2}$ Arindam Pande, ${ }^{3}$ \\ Ranjan K Shetty ${ }^{1}$
}

${ }^{1}$ Department of Cardiology, Kasturba Medical College, Manipal, Karnataka, India ${ }^{2}$ Institute of Post-Graduate Medical Education and Research, Kolkata, West Bengal, India

${ }^{3}$ IPGMER \& SSKM Hospital, Kolkata, West Bengal, India

\section{Correspondence to} Dr Naveen Chandra Ganiga Sanjeeva,

drnaveenchandrags@gmail.com

Accepted 5 February 2015

CrossMark

\section{To cite: Ganiga}

Sanjeeva NC, Sarkar A

Pande A, et al. BMJ Case Rep Published online:

[please include Day Month Year] doi:10.1136/bcr-2014204885

\section{DESCRIPTION}

An 8-year-old boy presented to us with exertional breathlessness with cyanosis. Cardiovascular examination findings were suggestive of atrial septal defect (ASD). Chest X-ray showed right ventricular hypertrophy and prominent right pulmonary artery with prominent superior vena cava (SVC) shadow (figure 1). A transthoracic echocardiogram confirmed a non-restrictive ASD flowing right to left with dilated right-sided chambers. Echocardiogram examination also revealed absence of pulmonary

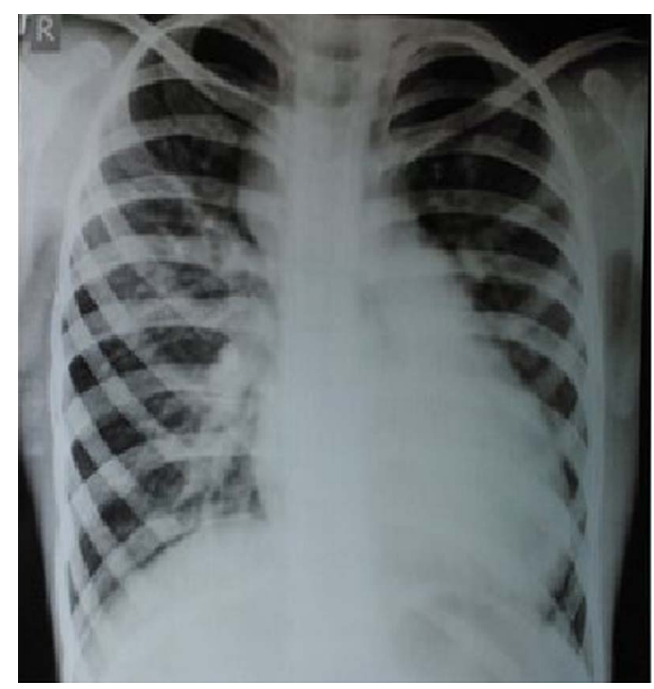

Figure 1 Chest X-ray showing cardiomegaly, prominent right descending pulmonary artery with prominent superior vena cava shadow.

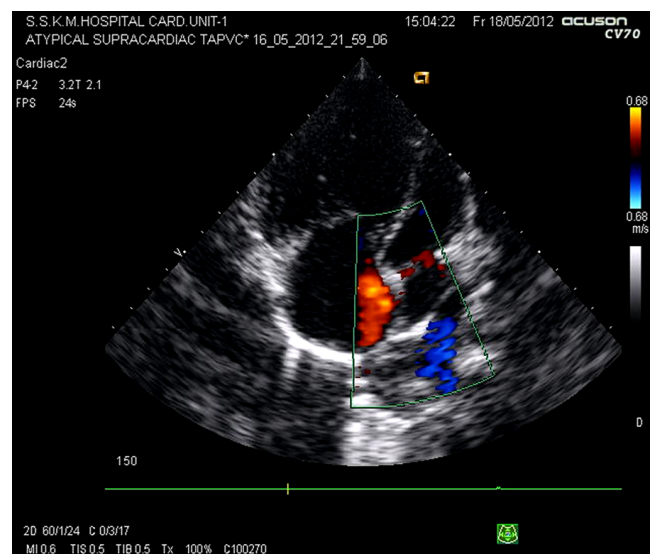

Video 1 Two-dimensional echocardiography apical four-chamber view showing right atrial and right ventricular dilation, absent pulmonary venous connections to the left atrium vein and a common venous chamber posterior to the left atrium.

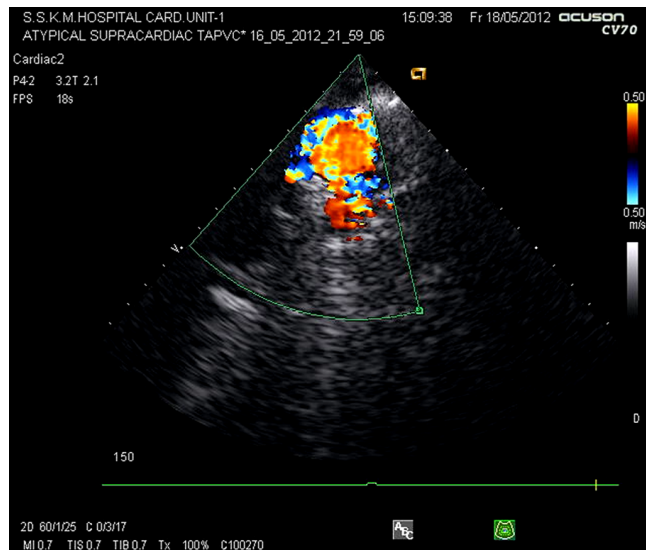

Video 2 Two-dimensional echocardiography with colour Doppler, suprasternal view, showing a flow in the vertical vein draining directly into the superior vena cava.

venous connections to left atrium suggestive of an associated total anomalous pulmonary venous connection (TAPVC; video 1). On suprasternal views, the pulmonary venous confluence was seen draining into the vertical vein and then into the SVC on the right side of the spine (video 2). A contrast CT was carried out with three-dimensional reconstruction, which showed the right and left pulmonary vein united at the vertical vein, which ascended on the right side of the spine and anterior to the pulmonary artery, to drain into the SVC (figures 2 and 3). Cardiac catheterisation was performed with a multipurpose catheter that was taken to the pulmonary venous confluence via SVC and vertical veins to demonstrate the venous drainage pattern (figure 4). Clinical investigations confirmed a non-obstructed supracardiac TAPVC with direct

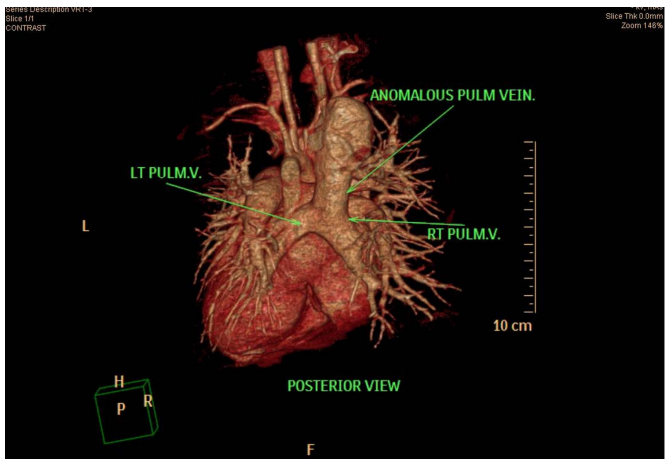

Figure 2 CT of the thorax with three-dimensional reconstruction image showing right and left pulmonary veins forming venous confluence, which is draining into the vertical vein. 


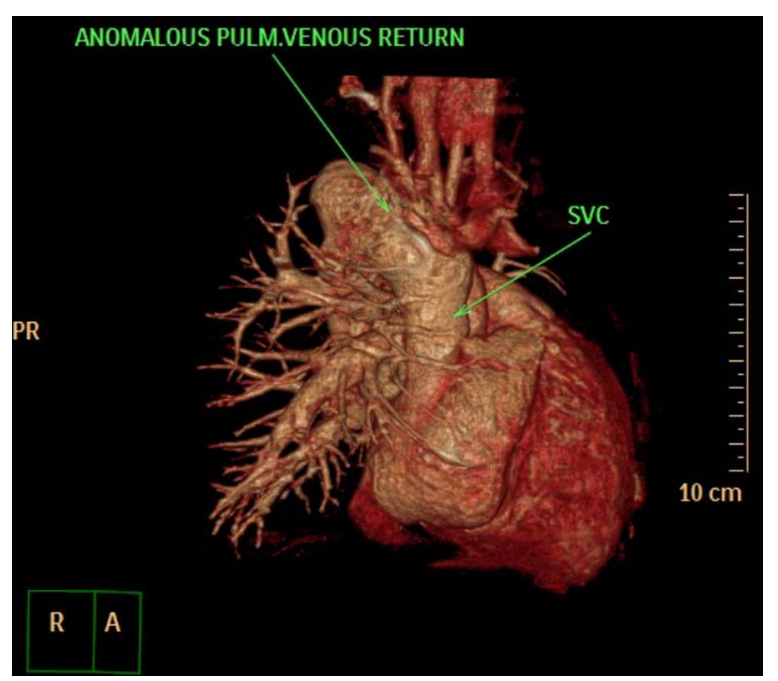

Figure 3 CT of the thorax with three-dimensional reconstruction image showing the vertical vein draining directly into the superior vena cava (SVC) at its superior aspect.

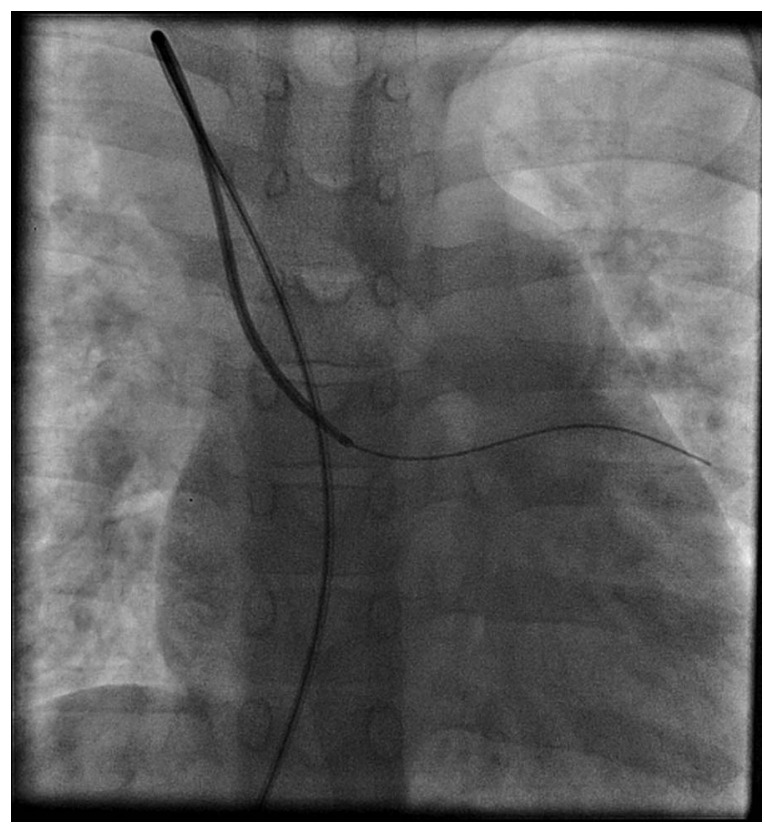

Figure 4 Cardiac catheterisation with multipurpose catheter and terumo wire showing the venous drainage pattern (catheter and wire course are from inferior vena cava, superior vena cava, vertical vein and left pulmonary vein). drainage of vertical veins to the SVC. The patient was sent for surgical correction under cardiopulmonary bypass. Incisions were made on the left atrium and pulmonary venous confluence, and direct anastomosis was performed. The patient postoperatively is acyanotic and functionally doing well.

Classically, in supracardiac TAPVC, the venous confluence drains into the SVC via the vertical and innominate veins. Very rarely, the vertical vein can drain directly into the SVC or azygous system of veins without draining into innominate veins. These drainage patterns are mostly obstructive in nature. ${ }^{12}$ In such cases, the classical 'snowman' appearance is not present on chest X-rays as the vertical vein traverses across the right side of the spine obscuring its shadow. In such cases, only the SVC shadow can be demonstrated in the X-ray, as seen in our index case (figure 1). Awareness of such uncommon drainage patterns is important as they pose a diagnostic and therapeutic challenge in diagnosis and treatment of such conditions.

\section{Learning points}

- Although most of the supracardiac total anomalous pulmonary venous connections (TAPVCs) drain via innominate veins, rare variants such as direct drainage of the vertical vein into the superior vena cava or azygous veins have also been reported.

- Most of these rare variants of supracardiac TAPVC are obstructive in nature.

- These variants are of particular importance during surgical repair because of the chances of injury to the right pulmonary artery and right bronchus because of its proximity.

Contributors NCGS, AS, AP and RKS were responsible for patient care, definition of intellectual content, literature search, manuscript preparation, manuscript editing, manuscript review, and is the guarantors.

Competing interests None.

Patient consent Obtained.

Provenance and peer review Not commissioned; externally peer reviewed.

\section{REFERENCES}

1 Delisle $\mathrm{G}$, Ando $\mathrm{M}$, Calder $\mathrm{AL}$, et al. Total anomalous pulmonary venous connection: report of 93 autopsied cases with emphasis on diagnostic and surgical considerations. Am Heart J 1976;91:99-122.

2 Edwards JE. Pathologic and developmental considerations in anomalous pulmonary venous connection. Proc Staff Meet Mayo Clin 1953;28:441-52. 
Copyright 2015 BMJ Publishing Group. All rights reserved. For permission to reuse any of this content visit http://group.bmj.com/group/rights-licensing/permissions.

BMJ Case Report Fellows may re-use this article for personal use and teaching without any further permission.

Become a Fellow of BMJ Case Reports today and you can:

- Submit as many cases as you like

- Enjoy fast sympathetic peer review and rapid publication of accepted articles

- Access all the published articles

- Re-use any of the published material for personal use and teaching without further permission

For information on Institutional Fellowships contact consortiasales@bmjgroup.com

Visit casereports.bmj.com for more articles like this and to become a Fellow 